\title{
EFFECTS OF SOCIAL SHOPPING BEHAVIOR FROM THE PERSPECTIVE OF COLLECTIVE INTELLIGENCE AND DISSONANCE
}

\author{
I-ping Chiang \\ National Taipei University, Taiwan \\ Email: ipchiang@mail.ntpu.edu.tw \\ Chia-Chi Liang \\ National Taipei University, Taiwan \\ Email:ntpu.im.iplab@gmail.com \\ Wan-Ling Yang \\ National Taipei University, Taiwan \\ Email: ntpu.im.iplab@gmail.com
}

\begin{abstract}
People increasingly depend on the consumer experiences of a virtual community when making purchasing decisions. Potential consumers search for different types of electronic word of mouth when choosing a product to purchase. Social shopping has numerous advantages, including community-based interaction and the sharing of consumer experiences; however, few studies have focused on measuring the effects of social shopping. This study established a conceptual framework for measuring the effects of social shopping activities, comprising the key elements of (1) the perceptions of social shopping activities, (2) collective intelligence and dissonance, and (3) the consequences of social shopping. This study collected 836 valid Internet user responses to an online survey. Partial least squares regression was used to analyze the relationship between the elements and to measure the effects in different social shopping stimuli. The purpose of this study is to build a model of social shopping activities and verified by PLS to establish a theoretical framework. The study found that only cognitive diversity in each path has no significant impact on collective intelligence, management mechanisms on imbalance, and imbalance on community loyalty. Moreover, most of the user perceptions summarized in this research can produce subsequent benefits and behaviors.
\end{abstract}

Keywords: Social Shopping, Collective Intelligence, Dissonance, Purchase Intention

\section{INTRODUCTION}

According to eMarketer, the number of users on social network sites has reached 1.6 billion, which is equivalent to one in every five people worldwide [1]. People chat or communicate with other users, search for information, or refer to electronic word of mouth (e-WOM) in the virtual community. Social Labs showed that social network sites are effective platforms for discovering desirable merchandise [2]. They reported that $62 \%$ of online shoppers had read accounts by friends on consumer experience, and 
$75 \%$ had followed links to their Facebook friends' posts on retailer websites; furthermore, $53 \%$ of online shoppers had purchased products because they were influenced by the virtual community. A report by PowerReviews investigating the influence of virtual communities on individual purchase decisions indicated that the interaction between members of the community was a critical factor [3]. User-oriented information on consumer experiences or opinions about products influences a person's purchase intention. Furthermore, enterprises have increasingly noticed the potential business opportunities offered by the virtual community. The accurate monitoring of online trends and social shopping influences is considered a valuable business investment.

Most of the past research focused on online word-of-mouth [4, 5], or the level of community participation and member sharing behavior [6, 7]. Besides, related research on social shopping and social commerce, such as studying how to manage brand pages on Facebook, and the interaction between brand pages and consumers' « ', can effectively increase brand exposure and discussion awareness [8]; from the personality traits and other related influencing factors of consumers being discussed, because consumers' personality traits and other factors are different, there will be different consumer behaviors on the social media [9]; in addition, there are also different perspectives from using mobile phones to shop online and discuss the shopping experience and consumption intentions such as tolerance of using mobile phones for online shopping [10]. These are unable to fully explain how a series of social shopping processes. However, through positive/negative post contents and response, can explore the process of consumers' cognitive changes in social shopping activities. This study intends to summarize the two major constructs of collective intelligence and dissonance from consumers' social shopping behavior activities to consumers' influences. In the past, there were few works of literature on the research topic of "social shopping". In the past, cognitive dissonance was rarely extended to virtual society (e.g. Redondo \& Charron[11]; Juvan \& Dolnicar [12]), empirical research is still lacking.

This study was conducted to elucidate social shopping behavior based on community interactions. It investigated collective intelligence and dissonance, and evaluated whether social shopping circumstances influenced a user's purchase intention and community loyalty. Various scenarios of social shopping were designed by comparing different proportions of positive and negative information. This paper summarizes these analyses and draws conclusions on the following topics:

- The perceptions of social shopping activities, collective intelligence, dissonance, and the consequences of social shopping inferred in the literature.

- A measurement model of social shopping, connecting the perceptions of social shopping activities to purchase intention and community loyalty.

The differences between social shopping messages using positive and negative articles and responses, the outcomes, and the different influences of social shopping activities. 


\section{LITERATURE REVIEW}

\subsection{Social Shopping}

Rouse studied social shopping is a type of social commerce, but online shopping behavior involves shopping experience or e-WOM [13]. Kim pointed out another feature of social shopping is the relationships and social interactions among online users [14]. Walker indicated that social shopping can help participants make more efficient purchasing decisions, for example, determining the cheapest price or best product with the same function [15].

Information on social shopping activities can be a reliable reference source, enabling the rapid identification of products matching user preferences. Because of the availability of online searching and sharing, and the diversity of positive and negative information, social shopping may cause users to turn to other brands or reduce their purchase intention [16]. Web 2.0 increased the influence of social shopping by facilitating online user interactions, which drove the development of social shopping activities.

\subsection{Perceptions of Social Shopping Activities}

\subsubsection{Cognitive Diversity}

Stich defined cognitive diversity as different people giving inconsistent responses to the same environment [17]; the apparent differences between these people are the reasons for their different thoughts. Cachia, Compañó, \& Da suggested that each member in a community has his or her own position and function, and that each contributes knowledge and opinions to help solve other members' questions according to his or her experience and profession. Communities typically contain different ideas and information [18].

\subsubsection{Decentralization}

Under Web 2.0, users are able to share their opinions on the Internet; Furtado et al. indicated that, consequently, neither consumer nor enterprises have narrowed the cognitive gap of product information [19]. Furthermore, from the perspective of community collaboration, a small contribution from each member is regarded as a valuable benefit for the community [20]. Therefore, the participation of each member is crucial to the community.

\subsubsection{Aggregation Mechanism}

The Internet contains an enormous amount of information, and e-WOM exists in numerous forms on different platforms, such as social media, social network sites, and blogs. Hsu and Liao demonstrated the necessity of developing an efficient and accurate mechanism for managing this huge amount of information [21]. Integrating valuable content and marking the importance of articles can help users quickly find information; Zha, Zhang, Yan, and Xiao [22] considered this indispensable for the virtual community in establishing efficient information management [22]. 


\subsubsection{Information Quality}

Virtual community information includes user-generated content, product information, and news about brands. Kim and Park suggested that social commerce is based on a group's relationships, and that the information quality provided by a community influences member trust in the community [14]. If the information is sufficiently reliable and professional, it influences not only a user's product decisions but also his or her intention of continuing participation in the community [15] [23-24].

\subsubsection{Information Exchange}

Lu \& Yang considered the information exchange of a community as the learning progress of a series action, including knowledge sharing, searching for information, and browsing an article's responses [25]. Information exchange behavior involves instantaneity, reliability, associativity, and comprehensibility. All of these features influence the operation of a community.

Kim and Ko also found that a higher frequency of discussion among members about a product gives consumers an impression of that product, thereby affecting consumer purchasing decisions [26].

\subsection{Collective Intelligence and Dissonance}

\subsubsection{Collective Intelligence}

Bonabeau regarded collective intelligence as a process constituting the strength of crowds and integrating each participant's opinions to solve a problem [27]; thus, no real leader exists to give instructions. Collective intelligence can also be considered as the cognition of a group, which means that group members have a common understanding of an object [28]. Surowiecki and Silverman indicated that collective intelligence includes individual diversity, decentralization, and an aggregation mechanism [29].

Zha et al. found that the user-generated content created by a member is beneficial to the production of collective intelligence [22]. Furthermore, the individual differences of a community inspire unexpected ideas [30]. Therefore, we proposed the following hypothesis:

H1: When a consumer's perceptions of social shopping activities is stronger, collective intelligence is higher.

\subsubsection{Dissonance}

Festinger proposed a dissonance theory concerning the state of mental conflict [31]. The theory describes the discomfort experienced by an individual who simultaneously holds two or more contradictory beliefs, ideas, or values. When a person receives information inconsistent with his or her original cognition, he or she shows negative emotions, such as feeling upset, angry, or disappointed. Boyce and Greer argued that in such inconsistent situations, people attempt to make a change to reach an equilibrium point of cognition or reduce the degree of discomfort [32]. Sweeney and Hausknecht contended that consumers also experience dissonance at the marketing level, and that negative emotions influence their consumer behavior [33]. Websites involving social shopping activities typically contain negative product reviews, which 
might place users in a dissonant situation [34]. Therefore, we proposed the following hypothesis:

H2: When a consumer's perceptions of social shopping activities are stronger, the degree of dissonance is lower.

\subsection{Consequences of Social Shopping}

\subsubsection{Purchase Intention and Community Loyalty}

Ajzen and Fishbein considered that for consumers, purchase intention is the objective-oriented of the merchandise [35]. Lu, Chang, and Chang showed that a consumer's attitude toward a product has a direct effect on his or her purchase behavior [36]. In their study, they found that online product reviews exerted varying degrees of influence on a consumer's purchase decision, and they compared the difference between bloggers and ordinary people. This means social shopping information influences a user's purchasing decision. Kim and Park argued that e-WOM in the community affects a consumer's impression of a business brand [14]. Trigo and Coelho indicated that collective intelligence derived from the information exchange behavior in consumer decision making informs purchase decisions [37].

When users believe that a community is valuable, they have the intention of making return visits [38]. Kim, Choi, and Han argued that if a community provides abundant useful information to a user, it strengthens the relationship between the member and the community [39]. Hautz, Füller, Hutter, and Thürridl explained that user-generated content was willingly shared and recommended by users in their study [40]. Furthermore, when a community helps people efficiently find products, loyalty toward the community increases. However, when a community's referral value does not match the user's thoughts, he or she may look to another platform to reduce the feeling of discomfort. Koller and Salzberger showed that it is possible to create a dissonance situation before the purchase (instead of after), such that the consumer questions his or her purchase decision before acting [41]. When an information-oriented community provides content that cannot be trusted, it drastically reduces the number of users [34]. On the basis of this discourse, we proposed the following hypotheses:

H3a: The collective intelligence of social shopping activities increases a consumer's purchase intention.

H3b: The collective intelligence of social shopping activities increases a consumer's community loyalty.

H4a: Dissonance in social shopping activities reduces a consumer's purchase intention. loyalty.

H4b: Dissonance in social shopping activities reduces a consumer's community

\section{MEASUREMENT}

This study used an online survey consisting of 46 questions to gather data. Two questions were asked to ensure the reliability of the respondents: "Do you habitually use a food-oriented virtual community?" and "How many of the following restaurant brands are you familiar with?" (for which a list was provided). Respondents could 
continue the questionnaire if they chose restaurant brands we had shown in the social shopping message of research. Reponses were scored on a 6-point Likert scale, ranging from 1 (strongly disagree) to 6 (strongly agree). To ensure sampling conformed to the general population of Internet users in Taiwan, the sampling ratio for Internet users was based on data from the Taiwan Network Information Center (TWNIC), the only official and nonprofit organization offering Internet statistics in Taiwan. Our study used age and gender quotas to match the demographics of the participants with those of recent Internet users provided by the TWNIC.

Finally, this study collected 836 valid Internet user samples. Of these respondents, $384(45.90 \%)$ were male and $452(54.10 \%)$ were female. The ages of respondents ranged from 20 to 80 years, as shown in Table 1.

Table1. Demographic data

\begin{tabular}{ccc}
\hline Gender & Count & Percentage \\
\hline Male & 384 & $45.9 \%$ \\
Female & 452 & $54.1 \%$ \\
Total & 836 & $100.0 \%$ \\
\hline Age & Count & Percentage \\
\hline $20-24$ & 103 & $12.2 \%$ \\
$25-29$ & 110 & $13.2 \%$ \\
$30-34$ & 185 & $22.1 \%$ \\
$35-39$ & 175 & $20.9 \%$ \\
Above 40 & 263 & $31.5 \%$ \\
Total & 836 & $100.0 \%$ \\
\hline
\end{tabular}

The research team in this study selected articles and comments based on online word-of-mouth and classified whether they were positive or negative based on the scores, the content of the post, and the response. Then through a pilot study of about 30 people, and under the situation that without prompt. The study designed four scenarios with the control variables of positive or negative articles and positive or negative comments. We operated two control variables split into four groups (namely, two types of article and two types of comment). The numbers of valid samples among the groups were approximately the same, as shown in Table 2.

Table2. The effective samples of each scenario

\begin{tabular}{ccc}
\hline Groups & Count & Percentage \\
\hline Group (A). Positive article x Positive comment & 202 & $24.2 \%$ \\
Group (B). Positive article x Negative comment & 210 & $25.1 \%$ \\
Group (C). Negative article x Positive comment & 211 & $25.2 \%$ \\
Group (D). Negative article x Negative comment & 213 & $25.5 \%$ \\
All Groups & 836 & $100.0 \%$ \\
\hline
\end{tabular}


This study measured nine constructs split into three parts. The first part included perceptions of social shopping: cognitive diversity, decentralization, aggregation mechanism, information quality, and information exchange. The second part included collective intelligence and dissonance. Finally, we considered two behaviors influenced by social shopping: purchase intention and community loyalty.

According to Cooper \& Schindler (2003), Cronbach's alpha reliability coefficient above 0.7 indicates the minimum standard for passing reliability, higher than 0.8 indicates that the reliability is better, and above 0.9 indicates has the extremely high reliability. In this study, SmartPLS 2.0 software was used for confirmatory factor analysis (CFA) to detect the convergence validity and discriminant validity of each construct. The important measurement values include combined reliability (CR) and average variation extraction (AVE). Fornell \& Larcker (1981) pointed out that the three criteria for evaluating convergent validity are: first, the fully standardized factor load must be greater than 0.5 ; second, the combined reliability (CR) must be greater than 0.7 , and finally, the average the variation extraction amount (AVE) is greater than 0.5 . A validity analysis revealed Cronbach alphas exceeding 0.8 , composite reliability $(\mathrm{CR})$ exceeding 0.8 , and average variance extracted (AVE) exceeding 0.5 for all dimensions. The reliability statistics for each construct are shown in Table 3.

Table3. Reliability statistics of each construct

\begin{tabular}{|c|c|c|c|}
\hline & Cronbach 's Alpha & $\mathrm{CR}$ & AVE \\
\hline Cognitive Diversity & 0.89 & 0.92 & 0.64 \\
\hline Decentralization & 0.83 & 0.90 & 0.75 \\
\hline Aggregation Mechanism & 0.82 & 0.90 & 0.74 \\
\hline Information Quality & 0.91 & 0.92 & 0.71 \\
\hline \multirow[t]{2}{*}{ Information Exchange } & 0.88 & 0.90 & 0.74 \\
\hline & Cronbach 's Alpha & $\mathrm{CR}$ & AVE \\
\hline Collective Intelligence & 0.89 & 0.93 & 0.70 \\
\hline \multirow[t]{2}{*}{ Dissonance } & 0.83 & 0.91 & 0.63 \\
\hline & Cronbach 's Alpha & $\mathrm{CR}$ & AVE \\
\hline Purchase Intention & 0.90 & 0.96 & 0.89 \\
\hline Community Loyalty & 0.94 & 0.91 & 0.64 \\
\hline
\end{tabular}

\section{RESULTS AND ANALYSIS}

We collected individually valid samples for four subsample groups in this study. Each group was given a different social shopping scenario, considering the real social shopping environment, user communications, and interactions and information exchange with others: Group 1 (positive article with positive comment), Group 2 (positive article with negative comment), Group 3 (negative article with positive comment), and Group 4 (negative article with negative comment). We used SmartPLS (Version 2.0, SmartPLS GmbH) to complete a multisample test for each group's model, and the different model paths were compared. 
(1) Group 1 (positive article-positive comment)

Note: $* \mathrm{p}<0.05 ; * * \mathrm{p}<0.01$

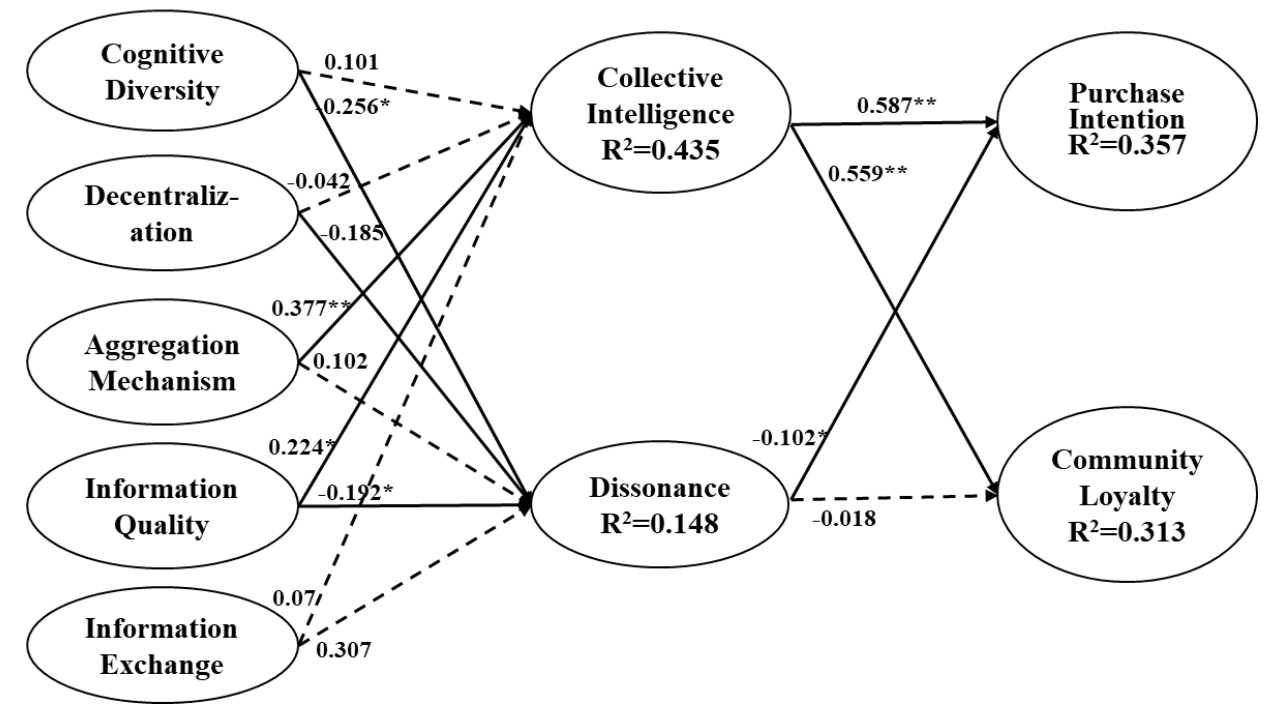

Figure 1. Data analysis of group 1

The results from the data analysis are shown in Figure 1. In the positive-positive social shopping scenario, when the perceptions of cognitive diversity and decentralization became stronger, this did not increase the user's collective intelligence $(\gamma=0.101, \mathrm{t}=0.97 ; \gamma=-0.042, \mathrm{t}=0.45)$; thus, H1a and H1b were not supported. However, a higher perception of the aggregation mechanism and of information quality led to greater collective intelligence $(\gamma=0.377, \mathrm{t}=3.72 ; \gamma=0.224, \mathrm{t}=2.48)$, supporting both H1c and H1d. A higher perception of information exchange did not influence a user's collective intelligence $(\gamma=0.07, \mathrm{t}=0.68)$, rejecting H1e. However, the perception of cognitive diversity reduced a user's dissonance $(\gamma=-0.256, t=2.21)$, supporting H2a. A perception of decentralization led to reduced dissonance $(\gamma=-0.185$, $\mathrm{t}=1.76)$, thereby supporting $\mathrm{H} 2 \mathrm{~b}$. Because a user's increased perception of the aggregation mechanism did not noticeably affect dissonance $(\gamma=0.102, \mathrm{t}=0.94), \mathrm{H} 2 \mathrm{c}$ was not supported. The perception of information quality reduced dissonance $(\gamma=$ $-0.192, \mathrm{t}=1.65)$, supporting $\mathrm{H} 2 \mathrm{~d}$. However, a stronger perception of information exchange did not reduce dissonance $(\gamma=0.307, \mathrm{t}=3.27)$, rejecting H2e. The collective intelligence of social shopping had a strong, positive correlation with a user's purchase intention and community loyalty $(\beta=0.587, \mathrm{t}=9.39 ; \beta=0.559, \mathrm{t}=10.5)$. Therefore, $\mathrm{H} 3 \mathrm{a}$ and $\mathrm{H} 3 \mathrm{~b}$ were supported. Dissonance reduced purchase intention $(\beta=-0.102, \mathrm{t}=$ 1.69), supporting $\mathrm{H} 4 \mathrm{a}$. However, dissonance exerted no noticeable influence on community loyalty $(\beta=-0.018, \mathrm{t}=0.32)$, rejecting $\mathrm{H} 4 \mathrm{~b}$. 
(2) Group 2 (positive articles-negative comments)

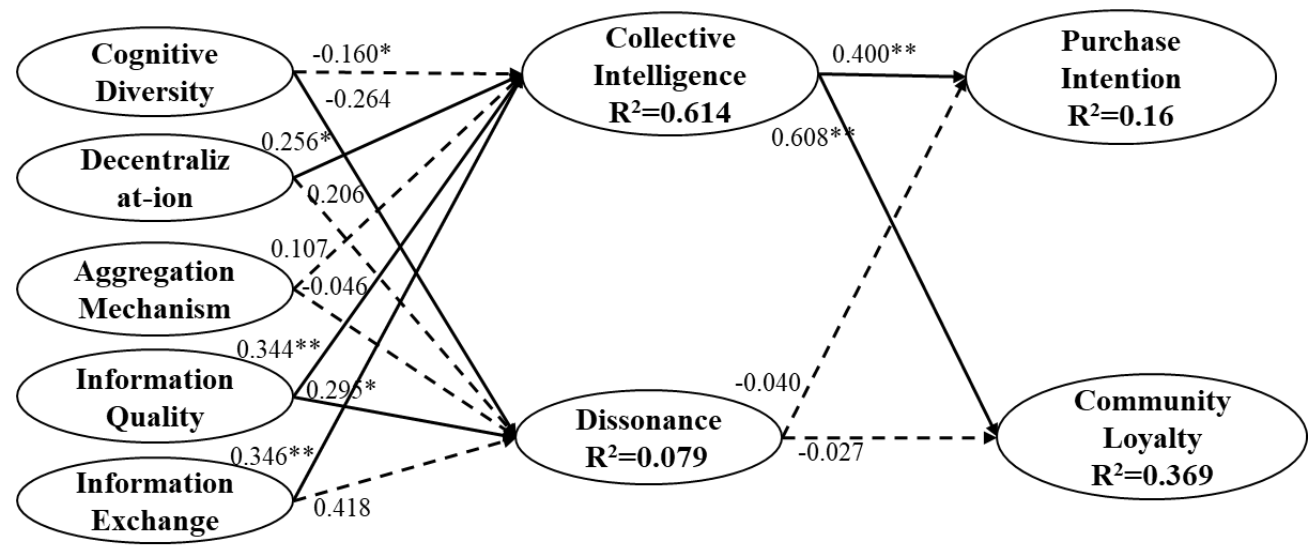

Note: ${ }^{*} \mathrm{p}<0.05 ; * * \mathrm{p}<0.01$

Figure 2. Data analysis of group 2

Figure 2 shows the results of Group 2. For the positive article with negative comment scenario, a stronger perception of cognitive diversity did not influence collective intelligence $(\gamma=-0.16, \mathrm{t}=1.59)$, thereby rejecting H1a. However, when a user's perception of decentralization increased, it had a positive relationship with collective intelligence $(\gamma=0.256, \mathrm{t}=2.54)$, supporting H1b. The perception of the aggregation mechanism did not correlate positively with collective intelligence $(\gamma=$ $0.107, \mathrm{t}=1.15)$, rejecting $\mathrm{H} 1 \mathrm{c}$. The analysis revealed that the perceptions of information quality and information exchange both correlated positively with collective intelligence $(\gamma=0.344, t=3.78 ; \gamma=0.346, t=3.23)$, supporting H1d and H1e. Furthermore, the perception of cognitive diversity reduced the degree of dissonance $(\gamma=-0.264, t=1.73)$, supporting H2a. However, the perceptions of decentralization and aggregation mechanism did not reduce a user's dissonance $(\gamma=0.203, \mathrm{t}=1.35 ; \gamma=206, \mathrm{t}=1.23)$; hence, $\mathrm{H} 2 \mathrm{~b}$ and $\mathrm{H} 2 \mathrm{c}$ were not supported. When the perception of information quality was increased, dissonance decreased $(\gamma=-0.295, \mathrm{t}=1.98)$, supporting $\mathrm{H} 2 \mathrm{~d}$. An increase in a user's perception of information exchange did not reduce dissonance $(\gamma=$ $0.418, \mathrm{t}=2.50)$, rejecting $\mathrm{H} 2 \mathrm{e}$. However, a greater collective intelligence in social shopping activities increased users' purchase intention and community loyalty $(\beta=$ $0.400, \mathrm{t}=6.04 ; \beta=0.608, \mathrm{t}=12.21)$, supporting $\mathrm{H} 3 \mathrm{a}$ and $\mathrm{H} 3 \mathrm{~b}$. Dissonance did not significantly influence purchase intentions or community loyalty $(\beta=-0.04, \mathrm{t}=0.51$; $\beta=-0.027, \mathrm{t}=0.37$ ); therefore, $\mathrm{H} 4 \mathrm{a}$ and $\mathrm{H} 4 \mathrm{~b}$ were not supported. 
(3) Group 3 (negative article-positive comment)

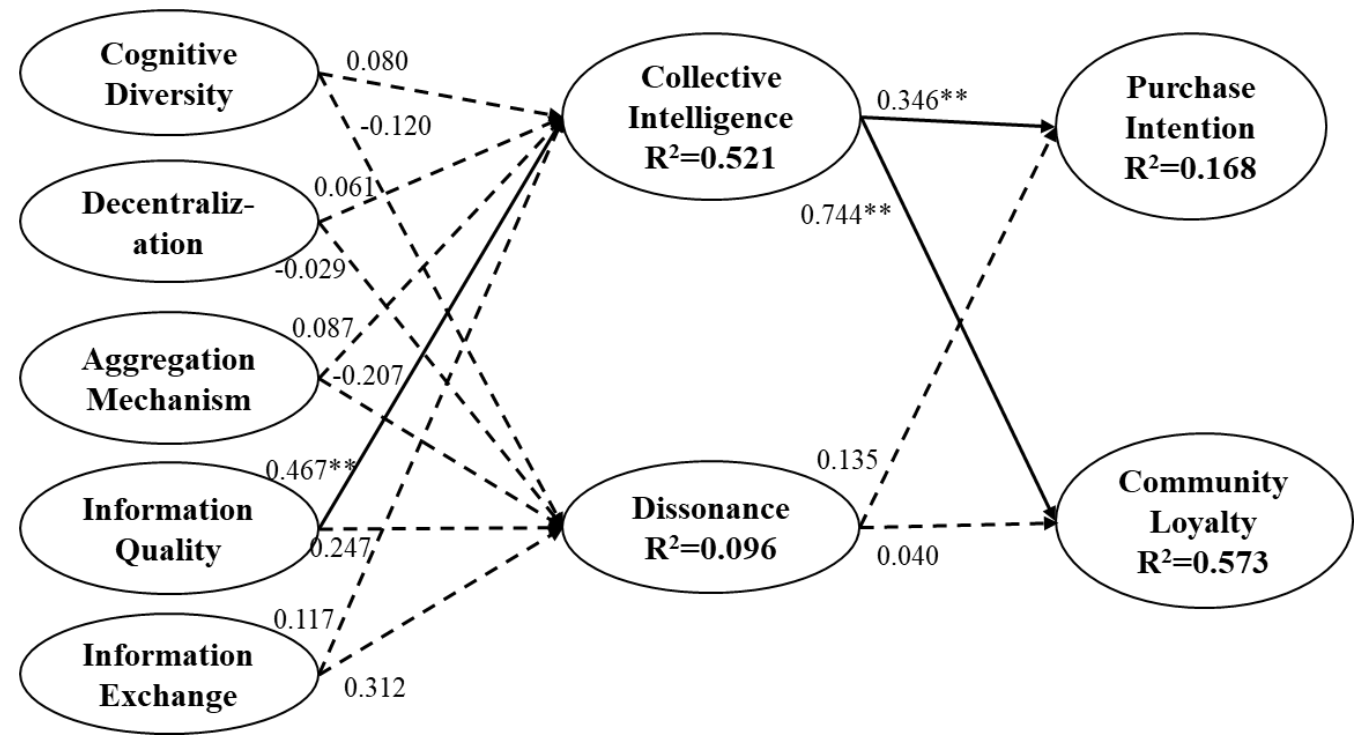

Note: ${ }^{*} \mathrm{p}<0.05 ; * * \mathrm{p}<0.01$

Figure 3. Data analysis of group 3

The results for the social shopping environment of a negative article with a positive comment are shown in Figure 3. The perceptions of cognitive diversity, decentralization, and aggregation mechanism did not increase collective intelligence $(\gamma$ $=0.08, \mathrm{t}=0.92 ; \gamma=0.061, \mathrm{t}=0.61 ; \gamma=0.087, \mathrm{t}=0.85)$; therefore, H1a, H1b, and H1c were not supported. An increase in the perception of information quality correlated positively with collective intelligence $(\gamma=-0.467, \mathrm{t}=4.34)$, supporting H1d. The perception of information exchange did not influence collective intelligence $(\gamma=0.117$, $\mathrm{t}=1.05)$, rejecting H1e. Furthermore, the perceptions of cognitive diversity, decentralization, and aggregation mechanism were not significant for reducing dissonance $(\gamma=-0.12, \mathrm{t}=1.14 ; \gamma=-0.029, \mathrm{t}=0.27 ; \gamma=-0.207, \mathrm{t}=1.44)$; therefore, $\mathrm{H} 2 \mathrm{a}, \mathrm{H} 2 \mathrm{~b}$, and $\mathrm{H} 2 \mathrm{c}$ were not supported. The perceptions of information quality and information exchange did not reduce dissonance $(\gamma=-0.247, \mathrm{t}=1.64 ; \gamma=-0.312, \mathrm{t}=$ 2.53 ); therefore, $\mathrm{H} 2 \mathrm{~d}$ and $\mathrm{H} 2 \mathrm{e}$ were not supported. However, collective intelligence positively influenced users' purchase intention and community loyalty $(\beta=0.346, \mathrm{t}=$ 4.88; $\beta=0.744, t=23.72$ ), supporting $\mathrm{H} 3 \mathrm{a}$ and $\mathrm{H} 3 \mathrm{~b}$. Dissonance did not influence purchase intention or community loyalty $(\beta=0.135, \mathrm{t}=1.59 ; \beta=0.04, \mathrm{t}=0.84)$, rejecting $\mathrm{H} 4 \mathrm{a}$ and $\mathrm{H} 4 \mathrm{~b}$. 
(4) Group 4 (negative article-negative comment)

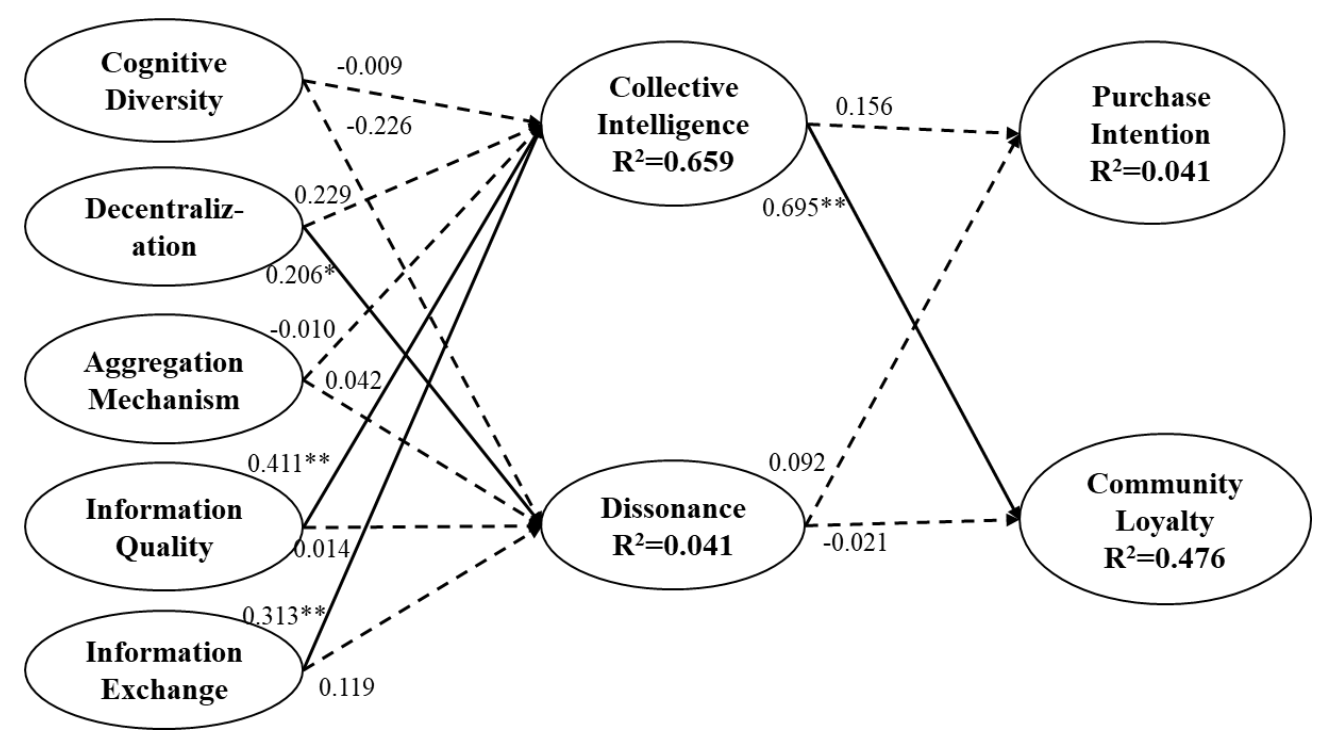

Note: ${ }^{*} \mathrm{p}<0.05 ; * * \mathrm{p}<0.01$

Figure 4. Data analysis of group 4

The results for the scenario of a negative article with a negative comment are shown in Figure 4. When the perception of cognitive diversity increased, it did not significantly influence collective intelligence $(\gamma=-0.009, \mathrm{t}=0.12)$, rejecting H1a. However, a stronger perception of decentralization increased collective intelligence $(\gamma$ $=0.206, \mathrm{t}=2.98$ ), supporting $\mathrm{H} 1 \mathrm{~b}$. An increase in the perception of aggregation mechanism did not influence collective intelligence $(\gamma=-0.010, t=0.11)$; hence, H1c was not supported. The perceptions of information quality and information exchange correlated positively with collective intelligence $(\gamma=0.411, \mathrm{t}=4.65 ; \gamma=0.313, \mathrm{t}=$ 3.68), supporting H1d and H1e. The perceptions of cognitive diversity, decentralization, and aggregation mechanism did not reduce dissonance $(\gamma=-0.226, \mathrm{t}=1.61 ; \gamma=0.229$, $\mathrm{t}=1.75 ; \gamma=0.042, \mathrm{t}=0.24)$; therefore, $\mathrm{H} 2 \mathrm{a}, \mathrm{H} 2 \mathrm{~b}$, and $\mathrm{H} 2 \mathrm{c}$ were not supported. Similarly, neither of the perceptions of information quality or information exchange significantly influenced dissonance $(\gamma=0.014, \mathrm{t}=0.09 ; \gamma=0.119, \mathrm{t}=0.77)$, rejecting $\mathrm{H} 2 \mathrm{~d}$ and $\mathrm{H} 2 \mathrm{e}$. Users' collective intelligence did not increase purchase intentions $(\beta=$ $0.158, \mathrm{t}=1.62)$; therefore, $\mathrm{H} 3 \mathrm{a}$ was not supported. Collective intelligence correlated positively with community loyalty $(\beta=0.695, \mathrm{t}=16.81)$, supporting H3b. Finally, dissonance did not reduce users' purchase intention or community loyalty $(\beta=0.092, \mathrm{t}$ $=0.78 ; \beta=-0.021, \mathrm{t}=0.38$ ), rejecting $\mathrm{H} 4 \mathrm{a}$ and $\mathrm{H} 4 \mathrm{~b}$.

\section{CONCLUSIONS}

This study developed a model of social shopping activities. From a literature review we summarized the perceptions and effects of social shopping activities, including the positive result of collective intelligence and the negative result of dissonance. Considering the large influence of social shopping activities on users, the behaviors of purchase intention and community loyalty were hypothesized to be influenced by social shopping activities. A survey was conducted according to Internet 
user demographics, and reliability and validity analyses were performed to ensure sample validity. Using different scenarios to examine the relationship between perceptions of social shopping (cognitive diversity, decentralization, aggregation mechanism, information quality, and information exchange), effects of social shopping (collective intelligence and dissonance), and influenced behavior (purchase intention and community loyalty). To conclude, we present the study's findings and provide some marketing suggestions.

\subsection{Influence of the social shopping message}

The study used a multisample test to verify the research model. To clarify the scenarios causing the different path processes, we discuss the following as context.

\subsubsection{Perceptions of social shopping and collective intelligence}

Comparing the results of the four groups, we found that the perception of aggregation mechanism was a necessary element in the positive-positive scenario; this means that users believe in the usefulness of an aggregation mechanism to compare the strengths of, for example, a product or restaurant. In both scenarios with negative comments, we found that the perceptions of decentralization and information exchange were strongly and positively correlated to collective intelligence. We believe that this is because active interactions among community members created higher probabilities of negative consumer experiences. Information quality, a critical element in a social shopping community, was significantly correlated to collective intelligence in all four groups; when information quality is high, the more valuable that information is to members of the community.

\subsubsection{Perceptions of social shopping and dissonance}

Participating in social shopping community activities shows individual differences that can reduce a user's dissonance. In the scenarios with positive articles, if more people give favorable reviews of a product, others will accept these reviews as being accurate. This can also reduce the community's dissonance. By contrast, negative articles did not reduce dissonance. This might be because the negative social shopping message included emotional words in the article, which makes it difficult to convince other members. To reduce dissonance, we found that the information quality of positive articles was crucial; more discussion of a product's advantages improved dissonance and acceptable for the cognitive inconsistent members. Therefore, to establish a better community and to reach a consensus among members, the quality of information should be maintained.

\subsubsection{Collective intelligence, dissonance, and purchase intention}

In general, collective intelligence had a positive relationship with purchase intention for all four groups. This means collective intelligence clearly influenced users' purchase intention. This finding is valuable for marketers who want to operate a social shopping community for increasing company sales. In addition, the dissonance of a virtual community did not directly affect members' purchase intention. This proves that most people like to hear a variety of opinions. Although this increases dissonance, it might not be sufficiently critical to affect purchase decision. However, the dissonance occurring in the positive-positive scenario reduced the users' purchase intention. We believe that this was because users doubted that the article was written by a genuine 
consumer. When a positive social shopping message is suspected to be written by a business, purchase intention decreases.

\subsubsection{Collective intelligence, dissonance, and community loyalty}

In the four groups, community loyalty was influenced significantly by collective intelligence. When a virtual community is valuable to its members, the intention of staying in this community increases, irrespective of positive or negative social shopping messages. As the community's value increases, members may recommend friends to join the community or share the information of this community. Dissonance does not reduce community loyalty because members are willing to hear other opinions; despite cognitive dissonance, the community has reference value.

\subsubsection{Conclusion}

This study focused on social shopping activities, a topic lacking in the literature. A model was developed to test the benefits of social shopping activities, with which the study successfully made connections among perceptions of social shopping activities, collective intelligence, dissonance, purchase intention, and community loyalty. Our results showed that the optimal scenario is a positive article with a negative comment; this promoted consumer efficiency and reduced the users' dissonance. We recommend that marketers not provide excessively positive appraisal of their products; when consumer experiences portray the strength of a product, a small amount of negative content should remain so that users may assess for themselves whether the product would satisfy their needs. Instead of removing all negative messages about a brand or product, we suggest keeping the interactive, dynamic content and improving the community's aggregation mechanism as an optimal method for promoting sales.

\subsection{Research limitations and development}

The study examined four scenarios of social shopping activities, but real situations cannot be sorted into only four types. Some positive or negative information can be mixed in ways that cannot be predicted. Thus, in the reality of social shopping activities, different types of social shopping messages might cause different results in consumers, and this cannot be tested. Furthermore, the respondents of the study were in Taiwan; respondents in another country may yield a different result. The study used a foodoriented virtual community to examine the model. Future studies should consider using other social shopping community types, or using two types of product to compare results. Finally, we found that the R2 of dissonance was generally lower than that of other constructs. This means that there might be other potential factors affecting the dissonance construct, which should be explored.

\section{REFERENCES}

[1] eMarketer, India Leads Worldwide Social Networking Growth, Retrieved on May 24, 2018, from: https://www.emarketer.com/Article/India-Leads-WorldwideSocial-Networking-Growth/1010396

[2] Social Labs, Social Impact Study: How Consumers See It, Retrieved on May 24, 2018,from:http://www.sociablelabs.com/hs-fs/hub/152867/file-18042759pdf/docs/social_impact_consumer_study_-_sociable_labs_3-25-2012.pdf

[3] PowerReviews, The 2011 Social Shopping Study, Retrieved on May 24, 2018, 
from: http://www.powerreviews.com/assets/download/Social_Shopping 2011_Briefl.pdf

[4] Park, C., \& Lee, T. M. (2009). Information direction, website reputation and eWOM effect: A moderating role of product type. Journal of Business Research, 62(1), 61-67.

[5] Brown, J., Broderick, A. J., \& Lee, N. (2007). Word of mouth communication within online communities: Conceptualizing the online social network. Journal of Interactive Marketing 21(3), 2-20.

[6] Chen, C. J., \& Hung, S. W. (2010). To give or to receive? Factors influencing members' knowledge sharing and community promotion in professional virtual communities. Information \& Management 47(4), 226-236.

[7] Park, J. H., Gu, B., Leung, A. C. M., \& Konana, P. (2014). An investigation of information sharing and seeking behaviors in online investment communities. Computers in Human Behavior 31(1), 1-12.

[8] Thongmak, Mathupayas. (2019). Do We Know What Contents Work for Social Commerce? A Case of Customer Engagement in Facebook Brand Pages. International Journal of Electronic Commerce Studies, 10(2), 141-174.

[9] Li, Zhen \& Hou, Avus. (2019). Online Purchase Preference and Personal Characteristics: A Moderation Approach. International Journal of Electronic Commerce Studies, 10(1), 1-21.

[10] Chen, C. W., \& Demirci, S. (2019). Factors Affecting Mobile Shoppers' Continuation Intention of Coffee Shop Online Store: A Perspective on Consumer Tolerance. International Journal of Electronic Commerce Studies, 10(2), 203-238.

[11] Redondo, I., \& Charron, J. P. (2013). The payment dilemma in movie and music downloads: An explanation through cognitive dissonance theory. Computers in Human Behavior, 29(5), 2037-2046.

[12] Juvan, E., \& Dolnicar, S. (2014). The attitude-behavior gap in sustainable tourism. Annals of Tourism Research, 48(8), 76-95.

[13] M., Rouse, Social Shopping, Retrieved on May 24, 2018, from: http://searchcio.techtarget.com/definition/social-shopping

[14] S. Kim and H. Park, Effects of various characteristics of social commerce (scommerce) on consumers' trust and trust performance. International Journal of Information Management, 33(2), 318-332, 2013.

[15] L. Walker, Social Shopping Definition, Retrieved on May 24, 2018, from: http://personalweb.about.com/od/socialcommerce/a/Social-ShoppingDefinition.htm

[16] B. Harris, What Is Social Shopping? Retrieved on May 24, 2018, from: http://www.wisegeek.com/what-is-social-shopping.htm

[17] S. P. Stich, The fragmentation of reason: Preface to a pragmatic theory of cognitive evaluation. The MIT Press, 1990.

[18] R. Cachia, R. Compañó, and O. Da Costa, Grasping the potential of online social networks for foresight. Technological Forecasting and Social Change, 74(8), 1179-1203, 2007.

[19] V. Furtado, L. Ayres, M. De Oliveira, E. Vasconcelos, C. Caminha, J. D’Orleans, and M. Belchior, Collective intelligence in law enforcement-The WikiCrimes system. Information Sciences, 180(1), 4-17, 2010.

[20] Y. Sun, Y. Fang, and K. H. Lim, Understanding sustained participation in transactional virtual communities. Decision Support Systems, 53(1), 12-22, 2012.

[21] C. L. Hsu and Y. C. Liao, Exploring the linkages between perceived information accessibility and microblog stickiness: The moderating role of a sense of 
community. Information \& Management, 51(7), 833-844, 2014.

[22] X. Zha, J. Zhang, Y. Yan, and Z. Xiao, User perceptions of e-quality of and affinity with virtual communities: The effect of individual differences. Computers in Human Behavior, 38, 185-195, 2014.

[23] H. F. Lin and G. G. Lee, Determinants of success for online communities: an empirical study. Behaviour \& Information Technology, 25(6), 479-488, 2006.

[24] R. Algesheimer, U. M. Dholakia, and A. Herrmann, The social influence of brand community: Evidence from European car clubs. Journal of Marketing, 69(3), 1934, 2005.

[25] Y. Lu and D. Yang, Information exchange in virtual communities under extreme disaster conditions. Decision Support Systems, 50(2), 529-538, 2011.

[26] A. J. Kim and E. Ko, Do social media marketing activities enhance customer equity? An empirical study of luxury fashion brand. Journal of Business Research, 65(10), 1480-1486, 2012.

[27] E. Bonabeau, Decisions 2.0: The power of collective intelligence. MIT Sloan Management Review, 50(2), 45-52, 2009.

[28] R. M. Palloff and K. Pratt, Collaborating online: Learning together in community (Vol. 32). John Wiley \& Sons, 2010.

[29] J. Surowiecki and M. P. Silverman, The wisdom of crowds. American Journal of Physics, 75(2), 190-192, 2007.

[30] S. J. Shin, T. Y. Kim, J. Y. Lee, and L. Bian, Cognitive team diversity and individual team member creativity: A cross-level interaction. Academy of Management Journal, 55(1), 197-212, 2012.

[31] L. Festinger, A theory of cognitive dissonance vol. 2: Stanford university press, 1957.

[32] G. Boyce and S. Greer, More than imagination: Making social and critical accounting real. Critical Perspectives on Accounting, 24(2), 105-112, 2013.

[33] J. C. Sweeney, D. Hausknecht, and G. N. Soutar, Cognitive dissonance after purchase: A multidimensional scale. Psychology \& Marketing, 17(5), 369-385, 2000.

[34] I. Lee and K. Lee, Social shopping promotions from a social merchant's perspective. Business Horizons, 55(5), 441-451, 2012.

[35] I. Ajzen and M. Fishbein, Attitude-behavior relations: A theoretical analysis and review of empirical research. Psychological Bulletin, 84(5), 888, 1977.

[36] L. C. Lu, W. P. Chang, and H. H. Chang, Consumer attitudes toward blogger's sponsored recommendations and purchase intention: The effect of sponsorship type, product type, and brand awareness. Computers in Human Behavior, 34(4), 258-266, 2014.

[37] P. Trigo and H. Coelho, Collective-Intelligence and Decision-Making. In Computational Intelligence for Engineering Systems, 61-76, 2011.

[38] E. Pöyry, P. Parvinen, and T. Malmivaara, Can we get from liking to buying? Behavioral differences in hedonic and utilitarian Facebook usage. Electronic Commerce Research and Applications, 12(4), 224-235, 2013.

[39] J. W. Kim, J. Choi, W. Qualls, and K. Han, It takes a marketplace community to raise brand commitment: the role of online communities. Journal of Marketing Management, 24(3-4), 409-431, 2008.

[40] J. Hautz, J. Füller, K. Hutter, and C. Thürridl, Let Users Generate Your Video Ads? The Impact of Video Source and Quality on Consumers' Perceptions and Intended Behaviors. Journal of Interactive Marketing, 28(1), 1-15, 2014.

[41] M. Koller and T. Salzberger, Cognitive dissonance as a relevant construct 
throughout the decision-making and consumption process-an empirical investigation related to a package tour. Journal of Customer Behaviour, 6(3), 217$227,2007$. 